\title{
Improving technology of producing non-alcoholic drinks using non-traditional raw materials
}

\section{Zoryana Romanova, Margarita Karputina, Oksana Kharkovska}

\author{
National University of Food Technologies, Kyiv, Ukraine
}

Keywords:

Raspberry

Malt extract

Stability

Extraction

Non-traditional

Article history:

Received

24.07.2019

Received in revised form 19.11.2019

Accepted

28.11.2019

\section{Corresponding \\ author:}

Zoryana Romanova

E-mail:

pani.zoriana@

gmail.com
DOI:

$10.24263 / 2310-$

1008-2019-7-2-11

\section{Abstract}

Introduction. The technology for the production of soft drinks using non-traditional raw materials with the aim of improving and expanding the range of products was investigated.

Materials and methods. Non-traditional raw materials were used to create the basis of a soft drink, in particular, strawberry and raspberry extract. The number of polyphenols in the objects of study were determined by spectrophotometric method. The optical density was measured in a cuvette with a layer thickness of $10 \mathrm{~mm}$ on a SF-46 spectrophotometer.

Results and discussion. The content of phenolic compounds is crucial for the stability of beverages. The using of morphological particles of raw materials makes it possible not only to improve the sensory properties of beverages, but also to extend their stability. Raspberry powder extract (2.30 and 1.02) had better phenolic compounds and rutin content than strawberry powder extract (1.50 and 0.30).

Available data indicate that the vegetative parts of plants contain no less biologically active substances, and sometimes even more than fruits, berries and vegetables, and their using allows to get concentrates and drinks from them with soft, piquant, harmoniously individual flavor and aroma.

Focusing on the rich content of valuable components, the leaves and stems of raspberries and strawberries were investigated for the using of additives to the concentrate of soft drinks.

Extract, which is prepared by boiling the chopped leaves and twigs in water for 3 minutes, has better sensory properties compared to other samples, so this method of preparing raspberry extract is optimal. Strawberries were excluded from the experiment due to the rich grassy tones in the taste and the corresponding aroma.

$0.75 \mathrm{~g}$ and $1.0 \mathrm{~g}$ in $100 \mathrm{~cm} 3$ of raspberry extract are best suited for use in order to create the basis for a soft drink.

Conclusions. Using of extracts of non-traditional plant materials will help to improve the sensory properties of the soft drink and expand the range. 


\section{Introduction}

The production of soft drinks is characterized by an extremely wide variety of raw materials [1] The use of juices, concentrates, infusions and extracts of vegetable raw materials, materials, flavors, emulsions, aromatic bases of other raw materials [3] The consumption of soft drinks not only compensates for the loss of moisture and salts by the body, but also enriches it with the vital biologically active substances [5]The growing consumer demand for quality beverages implies a constant search for technology improvements and the quality of finished products [6]

The purpose of research was to establish the perspective and feasibility of obtaining a drink enriched with biologically active substances of non-traditional raw materials.

\section{Literature review}

In the analysis of the development of the production of soft drinks in recent years, there is a clear tendency for their "naturalization" - from the use of the bases of artificial origin to identical natural and natural. Thus, the strategic direction of the industry development is the use of natural ingredients, which is in line with the improvement of existing technologies and the introduction of new ones [1].

One of the most important problems of the development of the beer and soft drinks industry is to improve the quality of products, marketing competitiveness, primarily cost reduction and improvement of the range [1] It can be achieved by developing and implementing production aimed at reducing the duration of the main production stages and improving the quality of beverages without significant costs of material and energy resources [1] One of the ways to solve this problem is to optimize the technology of soft drinks by using the so-called "basics" - basic intermediates, parts with the main set of prepared ingredients, improving the composition of the drink, providing it with preventive and health properties [2].

Basics for beverages are prepared mainly using concentrated citrus juices [2]. Usually used six times concentrated juice with a dry matter content of up to $65 \%$, pulp not more than $5 \%$. If necessary, add dyes, acid and preservatives [2].

Concentrates for soft drinks, as a rule, consist of 2 parts: aromatic and extractive [2]. The aromatic part A is prepared by dissolving the essential oils in alcohol. The strength of the aromatic part A is not less than $93 \%$ [2].

The extractive part B is prepared by mixing hydroalcoholic extracts of the herb St. John's wort, licorice root, Eleutrococcus (or levzey), dye and citric acid. This technology is energy and material costly [3] In addition, it requires a long time and a large amount of staff [3].

Development of technologies using the basics is relevant, therefore, their use in the beverage industry is cost-effective, as the technology is simplified, the loss of raw materials is reduced.

Within the framework of the considered trends, special relevance is development of various concentrated bases for non-alcoholic drinks. The solution of these tasks can be carried out in two directions: [4]

- the creation of efficient technologies for the processing of vegetable raw materials, provide maximum enrichment of the resulting infusions and extracts natural extractives. Creature concentrates based on extracts should be provided by different forms: liquid, highly concentrated, pasty, powdered, in the form of granules, etc; 
- $\quad$ enrichment of concentrated bases with essential nutrients and their premixes.

The latter direction has practical application in the development of soft drinks of various functional orientations [4].

The creation and improvement of technologies of concentrated bases on a natural basis is a prerequisite for the stable development of production of high-quality soft drinks.

Important is the integrated use of plant materials with the study of its active and minor components, ensuring the direction of the functional properties of concentrates and drinks based on them [4].

It was investigated the extraction of biologically active substances of lemon balm and calendula, hawthorn of red-blooded, black-fruited rowan, rose hips [5], medicinal sweetcorn, common yarrow, rose hips, hawthorn, roots of malt root [6], linden and elder flowers, raspberry, strawberry, currant, lemon balm and blueberry shoots [7] for the development of non-alcoholic drinks.

Publications on sweet potato studies show that the content of vitamins and minerals in it are comparable with various fruits [8] According to research sweet potatoes are rich in dietary fibre, minerals, vitamins, and antioxidants, such as phenolic acids, anthocyanins, tocopherol and $\beta$-carotene. They are an excellent source of vitamin A and a good source of potassium and vitamin $\mathrm{C}, \mathrm{B} 6$, riboflavin, copper, pantothetic acid and folic acid. The total antioxidant capacity determined by Oxygen radical absorbance capacity values of purplefleshed sweet potatoes were comparable with those of fruits (apples, apricot, avocado, cherries, grapefruit, orange, pears) and vegetables (broccoli, cabbages, eggplants, lettuces). Scientists reported that sweet potato cultivars whose roots are used for a beverage, paste, powder, an alcohol drink and a natural colorant have been developed. Consumption of noncarbonated drinks has become increasingly important. A number of fruit drinks manufactured from fruit juice and other natural ingredients are popular and are sold worldwide. Vegetable juices are also available. The demand for these drinks and beverages is largely based on their nutritive value, flavor, aroma and color. The quality of the sweet potato non-alcoholic beverage is within the acceptable quality range [8].

Berries and their products are very often recognized as "superfoods" [9] They possess high concentrations of phenolic compounds, which have been found in in vitro and in vivo studies to possess a range of biological activities, including anticancer and antiplatelet activities, as well as antioxidant properties [20]. However, these compounds may not influence the levels of oxidative stress biomarkers, and may even have prooxidative effects. In addition, the precise biological activities of berry phenolics are dependent on a range of factors including the class of phenolics, their concentration, the type of berry and even the form consumed, be it fresh berries, juice, wine, jam, oil or medicinal products. The addition of non-traditional vegetable raw materials not only expands the range, but also improves the performance of beverages, increases stability, gives the drink a feature that sets it apart from other beverages [9].

Available literature data [10] show that the vegetative parts of plants contain biologically active substances not less and sometimes more than fruits, berries and vegetables, and their use allows to get concentrates and drinks from them with soft, savory, harmoniously-individual flavor and aromatic.

Unfortunately, the problem of the integrated use of this raw materials is practically not solved.

Focusing on literary sources and the rich content of valuable components, the leaves and stalks of currant, raspberry and sea buckthorn were examined for the use of the additive as a concentrate soft drinks [10]. 
European raspberry, common raspberry or just raspberry (Rubus idaeus, local names: red raspberry, raspberry, bearberry) - bush family pink (Rosaceae) 1-2 m tall with annual vegetative shoots and lignified biennial stems that form flowering groves.

Raspberries contain pectins, which help remove various harmful substances from the body through the intestines, including cholesterol, and radioactive elements, so raspberries are recommended for people working in various heavy enterprises. Coumarins contained in raspberries improve blood clotting, and reduces the level of prothrombin [10].

Coumarins are concentrated in the leaves and in the branches. Anthocyanins strengthen capillaries, and reduce the tendency to sclerosis. Phytosterols reduce likelihood of atherosclerosis. Potassium contained in raspberry helps to improve the situation of people with a heart condition, as well as potassium [10].

There is iodine in raspberries, which has a beneficial effect on bronchitis, causing expectoration [10].

Strawberry is a very common berry. One of the organic acids found in strawberries neutralizes cancerous effects when smoking tobacco [12] .

Broth leaves (Folia) strawberries have long been used as a good remedy for insomnia. Strawberry is a good prophylactic against atherosclerosis and hypertension, it normalizes blood pressure and metabolism [12].

Tea with raspberries, strawberries or with their leaves, brewed together with tea leaves soothes pains in the stomach and in the intestines during gastritis. Raspberries contain a lot of copper, and copper is a part of many antidepressants, so raspberries should be eaten by those people who have a job associated with great nervous tension. Due to the fact that raspberry contains vitamin A, E, PP, C increases the tone and improves well-being [12].

The chemical composition of raspberry and strawberry leaves is rich: anthocyanidins and anthocyanins - water-soluble flavonoids (powerful antioxidants), phytosterols (kaempferol), tannins, essential oils, borneol, anthocyanins: callistephin, chrysanthemum, volatile compounds: verbenone, citronella, organic acids (citric, malic, cinnamic, hydroxybenzoic, gallic, chlorogenic, salicylic) and their esters, as well as ellagic acid, which is a natural phenolic antioxidant. Ascorbic acid, or vitamin C, is a strong antioxidant and chelating agent. As a result of the literature review and taking into account the importance of using plant extracts, we came to the conclusion that the use of raspberries and strawberries, namely extracts of leaves and twigs rich in phenolic components and coumarins and vitamins (Vit. C, Rutin) would be appropriate in the manufacture of soft drinks (Figure 1, 2) [13]. 


\section{— Food Technology}

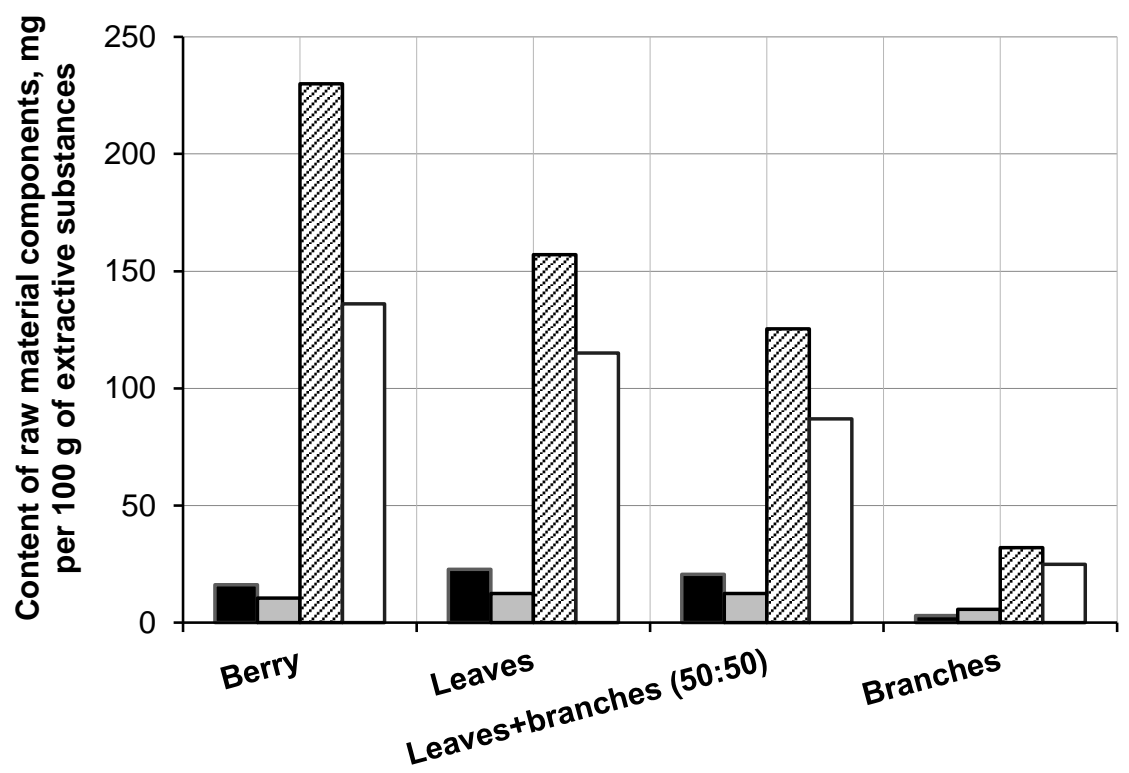

Morphological part of strawberry

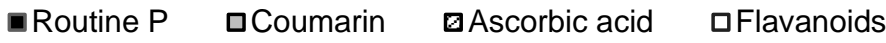

Figure 1. Content of strawberry components

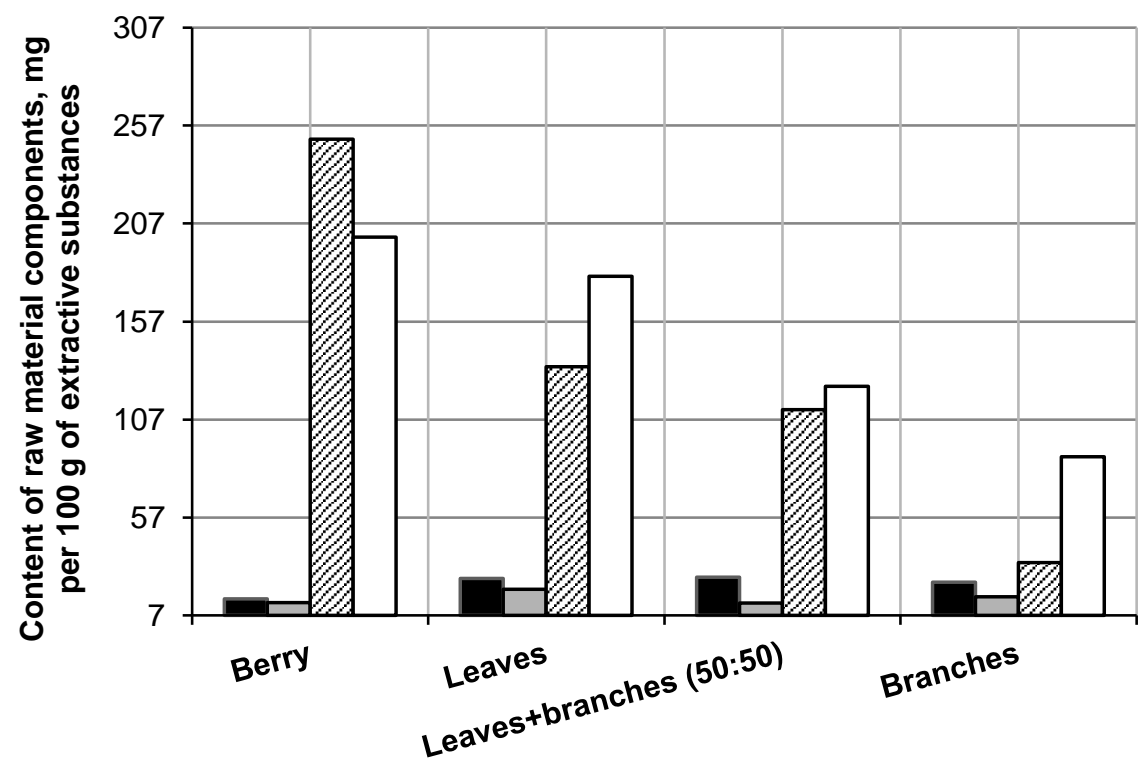

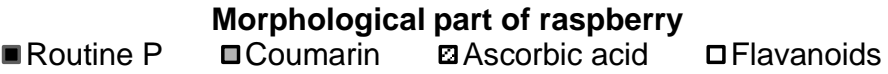

Figure 2. Content of the components of raspberry 


\section{Materials and methods}

To prepare the sample for analysis, the samples were ground to a powder state, after which they took a sample of $1.0000 \mathrm{~g}$, poured $50 \mathrm{ml}$ distilled water heated to $100{ }^{\circ} \mathrm{C}$. Maintained for 5 minutes, then filtered. Next, the aqueous extract was brought to a boil and boiled for 3 to 5 minutes. The next step was the exposure of the FDP in 55\% water-alcohol mixture for 2 days and then the FDP in $70 \%$ water-alcohol mixture for 2 days [14].

Determination of the pH. $100 \mathrm{ml}$ of sample is poured into a measuring glass, shaking for $10 \mathrm{~min}$ and immersing the $\mathrm{pH}$ electrode in the solution [15].

Titrated acidity. $100 \mathrm{~cm}^{3}$ of distilled water and $10 \mathrm{~cm}^{3}$ of sample are poured into a conical flask with a capacity of $250 \mathrm{~cm}^{3}$. 4-5 drops of an alcoholic solution of phenolphthalein with a mass concentration of $10 \mathrm{~g} / \mathrm{dm}^{3}$ are added to the solution and titrated with a solution of sodium hydroxide at a concentration of $0.1 \mathrm{~mol} / \mathrm{dm}^{3}$ until a pink color appears, which does not disappear for $30 \mathrm{~s}$ [15].

Determination of the amount of polyphenols. For a preliminary assessment of the qualitative composition of water or alcohol extract of raspberry and strawberry (leaflets and shoots), generally accepted qualitative reactions were performed, followed by determination of the phenolic components by spectrophotometric method [14]. The determination of the amount of polyphenols was performed spectrophotometrically by measuring the absorption index of the test sample after adding Folino-Checalteu reagent and 20\% sodium carbonate solution [16]. Optical density was measured in a cuvette with a layer thickness of $10 \mathrm{~mm}$ on a spectrophotometer SF-46 at the appropriate wavelength [16]. Recalculation of the percentage of the amount of polyphenols was carried out on chlorogenic acid.

The determination of the amount of soluble solids. The concentration of soluble solids in samples was measured using refractometer. On the lower prism of the refractometer, 2-3 drops of the test liquid are applied with a glass rod. The upper part of the prism is lowered, tightly applied to the lower stationary part of the prism and counted on a refractometer scale [15]

When calculating the readings, it is necessary to note the temperature at which the tests are carried out. If the temperature differs from $20^{\circ} \mathrm{C}$, make the appropriate amendment [15].

\section{Results and discussion}

The content of phenolic compounds, including rutin in powders obtained from raspberries and strawberries are presented in Table 1.

The results of total phenolic content proved that raspberry and strawberry powder, which were keeping the FDP in 55\% water-alcohol mixture for 2 days contain a highest amount of these compounds. But alcoholic extracts are material-intensive.

The content of phenolic compounds is crucial for the stability of beverages. The use of morphological particles of raw materials makes it possible not only to improve the sensory properties of beverages, but also to extend their stability.

Sample No. 2, which belongs to the extract of water powder from morphological particles of raspberry and strawberry, brought to a boil and boiled for 3-5 minutes on the content of phenolic components and aroma was suitable for further research $[16,20]$. 
Content of phenolic compounds

Table 1

\begin{tabular}{|l|c|c|c|c|}
\hline \multirow{2}{*}{ Processing option } & \multicolumn{2}{|c|}{ Raspberry powder } & \multicolumn{2}{c|}{ Strawberry powder } \\
\cline { 2 - 5 } & $\begin{array}{c}\text { Amount of } \\
\text { phenol }\end{array}$ & Rutin & $\begin{array}{c}\text { Amount of } \\
\text { phenol }\end{array}$ & Rutin \\
\hline $\begin{array}{l}\text { Water extract, heated to } 100{ }^{0} \mathrm{C}, \\
\text { sustained 10 min }\end{array}$ & 2,3 & 1,02 & 1,5 & 0,3 \\
\hline $\begin{array}{l}\text { The water extract, brought to a boil } \\
\text { and boiled for 3 to 5 minutes }\end{array}$ & 2,38 & 1,1 & 1,67 & 0,36 \\
\hline $\begin{array}{l}\text { Keeping the FDP in 55\% water- } \\
\text { alcohol mixture for 2 days }\end{array}$ & 2,63 & 1,84 & 1,8 & 0,64 \\
\hline $\begin{array}{l}\text { Keeping the FDP in 70\% water- } \\
\text { alcohol mixture for 2 days }\end{array}$ & 2,4 & 1,8 & 1,67 & 0,58 \\
\hline
\end{tabular}

Next, we conducted a study of the time of extraction by boiling, as evidenced by the data of Table 2.

Sensory characteristics of raspberry extract in boiling extraction

Table 2

\begin{tabular}{|c|c|c|c|}
\hline $\begin{array}{c}\text { Duration of } \\
\text { boiling, min }\end{array}$ & Colour & Aroma & Taste \\
\hline 1 & $\begin{array}{c}\text { Light, straw yellow, } \\
\text { poorly saturated, without } \\
\text { extraneous opacities }\end{array}$ & $\begin{array}{c}\text { Weak with hints } \\
\text { of spice }\end{array}$ & $\begin{array}{c}\text { Weak, unsaturated, } \\
\text { grassy }\end{array}$ \\
\hline 3 & $\begin{array}{c}\text { Light, straw-yellow, } \\
\text { medium intensity, without } \\
\text { other opacities }\end{array}$ & $\begin{array}{c}\text { Medium intensity, } \\
\text { there are shades of } \\
\text { spices and fresh } \\
\text { hay }\end{array}$ & $\begin{array}{c}\text { Pleasant, medium } \\
\text { rich shades of } \\
\text { meadow herbs }\end{array}$ \\
\hline 5 & $\begin{array}{c}\text { Saturated, straw-yellow } \\
\text { with a greenish tinge, } \\
\text { without extraneous } \\
\text { opacities }\end{array}$ & $\begin{array}{c}\text { Intense, } \\
\text { pronounced } \\
\text { shades of spices } \\
\text { and fresh hay }\end{array}$ & $\begin{array}{c}\text { Saturated, with a } \\
\text { slight bitterness, } \\
\text { with pronounced } \\
\text { tartness }\end{array}$ \\
\hline 8 & $\begin{array}{c}\text { Saturated, straw yellow, } \\
\text { with a greenish tint, } \\
\text { without extraneous } \\
\text { opacities }\end{array}$ & $\begin{array}{c}\text { Intense, there are } \\
\text { shades of burnt }\end{array}$ & $\begin{array}{c}\text { Saturated, with } \\
\text { unpleasant } \\
\text { bitterness and } \\
\text { tartness }\end{array}$ \\
\hline
\end{tabular}

According to the sensory evaluation of the investigated samples of raspberry powder extract, which are listed in Table 2, it was determined that the extract, which is prepared by boiling crushed leaves and twigs in water for 3 minutes, has better sensory properties compared to other samples, therefore this mode of preparation of raspberry extract is optimal. The strawberries from the experiment were excluded from the rich herbal tones in the flavor and the corresponding flavor. 
Table 3

Physical and chemical indicators of raspberry extract when extracted by boiling for 3 minutes

\begin{tabular}{|c|c|c|}
\hline $\begin{array}{c}\text { Duration } \\
\text { of boiling, min }\end{array}$ & pH & $\begin{array}{c}\text { Content } \\
\text { of dry substances, \% }\end{array}$ \\
\hline 1 & 6,81 & 0,5 \\
\hline 3 & 6,77 & 0,6 \\
\hline 6 & 6,81 & 0,6 \\
\hline 9 & 6,73 & 0,6 \\
\hline 11 & 6,57 & 0,7 \\
\hline
\end{tabular}

Samples were prepared according to the scheme below. Aqueous extract of aromatic raw materials were crushed, sieved to a homogeneous mass and took the sample in the amount of $0.25 ; 0.5 ; 0.75 ; 1.0 ; 1.25 \mathrm{~g}$ per $100 \mathrm{~cm} 3$ of water, boiled for 3 minutes. The data of sensory analysis entered in Table 4.

Sensory characteristics of the extract of raspberry leaves and twigs

Table 4

\begin{tabular}{|c|c|c|c|c|}
\hline $\begin{array}{c}\text { Amount } \\
\text { of } \\
\text { extract, }\end{array}$ & Appearance & Transparence & Aroma & Taste \\
\hline 0,25 & $\begin{array}{c}\text { Color light } \\
\text { straw } \\
\text { transparent }\end{array}$ & $\begin{array}{c}\text { Transparent, } \\
\text { without } \\
\text { sediment }\end{array}$ & $\begin{array}{c}\text { Straw } \\
\text { transparent, no } \\
\text { sediment grassy } \\
\text { aroma of forest } \\
\text { herbs }\end{array}$ & $\begin{array}{c}\text { Straw, grassy, } \\
\text { weak taste of } \\
\text { grass }\end{array}$ \\
\hline 0,5 & Straw & $\begin{array}{c}\text { Transparent, } \\
\text { without } \\
\text { sediment }\end{array}$ & Herbal & Forest scent \\
\hline 0,75 & Amber & $\begin{array}{c}\text { Transparent, } \\
\text { without } \\
\text { sediment }\end{array}$ & $\begin{array}{c}\text { Herbal, more } \\
\text { intense than the } \\
\text { previous one }\end{array}$ & $\begin{array}{c}\text { Harmonious } \\
\text { herbal with a } \\
\text { touch of } \\
\text { meadow herbs }\end{array}$ \\
\hline 1,0 & Amber & $\begin{array}{c}\text { Transparent, } \\
\text { without } \\
\text { sediment }\end{array}$ & Herbal, intense & Intense herbal \\
\hline 1,25 & Intensive & $\begin{array}{c}\text { Transparent, } \\
\text { without } \\
\text { hediment }\end{array}$ & $\begin{array}{c}\text { Intense, } \\
\text { intensely herbal }\end{array}$ & $\begin{array}{c}\text { Herbal, with } \\
\text { bitterness }\end{array}$ \\
\hline
\end{tabular}

General characteristics of solutions: with increasing concentrations, the color becomes more intense, all solutions are transparent, without sediment, the aroma increases, the taste becomes more intense. According to the results of the experiments, it was established that $0.75 \mathrm{~g}$ and $1.0 \mathrm{~g}$ in $100 \mathrm{~cm}^{3}$ of raspberry extract meets our goals best. For the convenience of preparing solutions, we select a sample of $1.0 \mathrm{~g}$ in $100 \mathrm{~cm}^{3}$ ( $1 \%$ aqueous solution).

In order to improve and expose the sensory characteristics of soft drink, we have suggested adding a poly-malt extract to the recipe. 
Available data indicate that the vegetative parts of plants contain no less biologically active substances, and sometimes even more than fruits, berries and vegetables [17], and their using allows to get concentrates and drinks from them with soft, piquant, harmoniously individual flavor and aroma.

Preparation of an aqueous solution of poly-malt extracts: in chemicals contained in substances quantitatively transferred into a volumetric flask per $100 \mathrm{~cm}^{3}$ and brought up to the mark with distilled water. Sensory indicators were determined.

The sensory analysis data are entered in Table 5.

Sensory characteristics with the introduction of poly-malt extract

Table 5

\begin{tabular}{|c|c|c|c|c|}
\hline $\begin{array}{l}\text { Amount of } \\
\text { extract, } \mathrm{ml}\end{array}$ & Appearance & Transparence & Aroma & Taste \\
\hline 1,5 & $\begin{array}{l}\text { Light, } \\
\text { transparent }\end{array}$ & $\begin{array}{c}\text { Transparent, } \\
\text { without } \\
\text { sediment }\end{array}$ & $\begin{array}{l}\text { Honey, with a } \\
\text { touch of herbs }\end{array}$ & $\begin{array}{c}\text { Honey, } \\
\text { slightly sweet }\end{array}$ \\
\hline 2,0 & $\begin{array}{l}\text { Light, } \\
\text { transparent }\end{array}$ & $\begin{array}{c}\text { Transparent, } \\
\text { without } \\
\text { sediment } \\
\end{array}$ & $\begin{array}{l}\text { Honey, with a } \\
\text { touch of herbs }\end{array}$ & $\begin{array}{c}\text { Honey, } \\
\text { slightly sweet }\end{array}$ \\
\hline 2,5 & $\begin{array}{l}\text { Light, } \\
\text { transparent }\end{array}$ & $\begin{array}{c}\text { Transparent, } \\
\text { without } \\
\text { sediment }\end{array}$ & $\begin{array}{l}\text { Honey, with a } \\
\text { touch of herbs }\end{array}$ & $\begin{array}{c}\text { Honey, } \\
\text { slightly sweet }\end{array}$ \\
\hline 3,0 & $\begin{array}{l}\text { Light, } \\
\text { transparent }\end{array}$ & $\begin{array}{c}\text { Transparent, } \\
\text { without } \\
\text { sediment }\end{array}$ & $\begin{array}{l}\text { Honey, with a } \\
\text { touch of herbs }\end{array}$ & $\begin{array}{c}\text { Honey, } \\
\text { slightly sweet, } \\
\text { but more } \\
\text { intense than } \\
\text { the previous } \\
\text { one }\end{array}$ \\
\hline 3,5 & $\begin{array}{l}\text { Light, } \\
\text { transparent }\end{array}$ & $\begin{array}{c}\text { Transparent, } \\
\text { without } \\
\text { sediment }\end{array}$ & $\begin{array}{l}\text { Honey, with a } \\
\text { touch of meadow } \\
\text { grass }\end{array}$ & $\begin{array}{c}\text { More opened } \\
\text { bouquet }\end{array}$ \\
\hline 4,0 & $\begin{array}{l}\text { Light, } \\
\text { transparent }\end{array}$ & $\begin{array}{c}\text { Transparent, } \\
\text { without } \\
\text { sediment }\end{array}$ & $\begin{array}{l}\text { Honey, with a } \\
\text { touch of herbs }\end{array}$ & $\begin{array}{c}\text { Opened } \\
\text { bouquet, as in } \\
\text { the previous } \\
\text { sample }\end{array}$ \\
\hline
\end{tabular}

General characteristics of solutions: all solutions are transparent, without sediment, despite the amount of extract (from 0.25 to $8.0 \mathrm{~g}$ ), the intensity increases with a large amount of extract. The aroma is enhanced with an increase in quality, but its shades change: up to 5 $\mathrm{g}$ per $100 \mathrm{~cm}^{3}$ - the characteristic shades of herbal and honey, after $5 \mathrm{~g}$ - possible malt shades of taste. Taste of honey participation in all samples. At the same time in a large amount of extract, sweetness grows, however, in samples 9 and 10 are sensitive to cold sharp shades, both in taste and in flavor. 
To determine the stability of the aqueous solution of the extract, the best samples (sample with an amount of extract of $3.0 \mathrm{~g}$ and a sample with an amount of extract of $4.0 \mathrm{~g}$ ) are kept in a refrigerator at room temperature for 3 days.

In the refrigerator, the samples became less turbid. Not steady precipitate falls out. After filtration, the filtrate was stable, a precipitate was not formed during storage for 3 days in the refrigerator.

As a result, we obtained a base consisting of a polysod extract and a $1 \%$ raspberry solution, and a glucose-fructose syrup of a certain concentration was chosen for sweetening.

Creation and improvement of technologies of concentrated bases on a natural basis is a prerequisite for the production of high quality soft drinks. According to the results of research, the selected recipe of the drink "With the taste of honey".

Formulation per $1000 \mathrm{l}$

Table 6

\begin{tabular}{|c|c|c|c|c|}
\hline Raw material & $\begin{array}{c}\text { Unit of } \\
\text { measurement }\end{array}$ & $\begin{array}{c}\text { Solids } \\
\text { content in } \\
\text { raw } \\
\text { materials, \% } \\
\text { of the mass. }\end{array}$ & $\begin{array}{c}\text { Consumption } \\
\text { rate }\end{array}$ & $\begin{array}{l}\text { Content of dry } \\
\text { substances } \\
\text { according to } \\
\text { the norms of } \\
\text { consumption, } \\
\% \text { mass }\end{array}$ \\
\hline $\begin{array}{l}\text { Glucose fructose } \\
\text { syrup }\end{array}$ & $\mathrm{kg}$ & 65,0 & 38,00 & 24,70 \\
\hline $\begin{array}{c}\text { Poly malt } \\
\text { extract }\end{array}$ & $\mathrm{kg}$ & 75,0 & 75,18 & 56,39 \\
\hline Citric acid & $\mathrm{kg}$ & 90,97 & 1,08 & 0,98 \\
\hline $\begin{array}{l}\text { Infusion of } \\
\text { raspberries } \\
\text { (branches, } \\
\text { leaves) }\end{array}$ & $\mathrm{kg}$ & & 0,30 & \\
\hline Flavor "Isindi" & $\mathrm{kg}$ & & 0,20 & \\
\hline $\begin{array}{c}\text { The amount of } \\
\text { acid, made with } \\
\text { the Poly malt } \\
\text { extract }\end{array}$ & $\mathrm{kg}$ & 0,05 & 75,18 & 0,04 \\
\hline Water & $\mathrm{dm}^{3}$ & \multicolumn{3}{|c|}{ up to 1000.00} \\
\hline Carbon dioxide & $\mathrm{kg}$ & & 4,15 & \\
\hline $\begin{array}{l}\text { Total solids in } \\
\text { the drink }\end{array}$ & $\mathrm{kg}$ & & & 82,07 \\
\hline
\end{tabular}

General characteristics of the solutions: all the solutions are transparent, without sediment, despite the amount of extract $(0.25$ to $8.0 \mathrm{~g})$, the intensity increases with a large amount of extract. The aroma increases with increasing quality, but its shades change: up to $5 \mathrm{~g}$ per $100 \mathrm{~cm}^{3}$ - characteristic shades of herbal and honey, after $5 \mathrm{~g}$ - malty flavors of taste 
are possible. Taste of honey involvement in all samples. At the same time sweetness increases in a large amount of the extract.

To determine the stability of the aqueous solution of the extract, the best samples (sample with extract amount of $3.0 \mathrm{~g}$ and sample with extract amount of $4.0 \mathrm{~g}$ ) are stored in the refrigerator at room temperature for 3 days.

In the refrigerator, the specimens became less cloudy. Resistant sediment is not maintained. After filtration, the filtrate was stable, the precipitate was not formed during storage for 3 days in the refrigerator.

\section{Conclusions}

1. The use of unconventional raw materials, such as extracts of raspberry, strawberry, or sea buckthorn, will help to expand the range of soft drinks.

2. Raspberry and strawberry extracts are a source of bioavailable active compounds (phenolic components, coumarins, ascorbic acid, micro- and macronutrients) which, due to their plant nature, have a mild effect on the body, but do not cause side effects. Raspberry leaf and twig extract is an unconventional raw material and has not yet been used in beverage production.

3. The proposed new drink: "With the taste of honey". As an unconventional raw material, which is used to prepare a drink extract from twigs and leaves of raspberry, which is characterized by a high content of biologically active substances.

4. The optimal dose of making the extract of raspberry leaf powder into the syrup for mixing is not more than $3,0 \mathrm{~cm}^{3}$ of $1 \%$ solution of grass.

\section{References}

1. Domaretsky V.A., Pribylsky V., Mikhailov M. (2005), The technology of extracts, concentrates and beverages from plant raw material, Vinnitsa.

2. Kosiv R., Kharandiuk T., Polyuzhyn L., Palianytsia L., Berezovska N. (2016), Optimization of main fermentation of high-gravity wort, Chemistry \& Chemical Technology, 10(3), pp. 349-353.

3. Schumann G. (2002), Non-alcoholic beverages: raw materials, technology standards, Gunther, Berlin.

4. Danilova L., Meletiev A., Arutyunyan T. (2003), Plant-based antioxidants in beer stabilization technology, East European Journal of Advanced Technology, 1, pp. 23-26.

5. Hoiko I., Simakhina H. (2014), Prospects for the using of wild raw materials for non-alcoholic beverages antioxidant action, Scientific works of NUFT, 20(6), pp. 219-226.

6. Ivanova V., Karyak N., (2011), Investigation of antioxidant properties of extracts from non-traditional plant raw materials, Scientific works of NUFT, 37, pp. 89-95.

7. Miron T. (2012), Enriched antioxidant activity of pear juice by supplementation with oregano and wild thyme extracts, The Annals of the University Dunarea de Jos of Galati Fascicle VI - Food Technology, 36(2), pp. 81-91.

8. Wireko-Manu F., Ellis W., Oduro I. (2010), Production of a non-alcoholic beverage from sweet potato, Kumasi, Ghana. 
9. Doboniy I., Bilko M., Korableva O. (2012), Scientific approach to composing compositions from aromatic raw materials for vermouth, Food Industry: Science and Technology, 1, pp. 17-19.

10. Filonova G., Grishkovsky B., Kovaleva I. (2011), Policomponent concentrates for functional drinks, Beer and drinks, 2, pp. 10-13.

11. Antolak H., Czyzowska A., Kregiel D. (2017), Antibacterial and Antiadhesive Activities of Extracts from Edible Plants against Soft Drink Spoilage, Journal of Food Protection, 80(1), pp. 25-34.

12. Codina I., Trujillo A.J., Ferragut V. (2016), Integrating Food Science and Engineering Knowledge into the Food Chain, Ttraditional food: general and consumer aspects, 10, pp. 345-357.

13. Koshova V., Dubitskaya T. (2008), New aspects of the use of non-traditional raw materials, Food industry, 6, pp. 57-59.

14. Karakaya S., Ei S., Tas A. (2001), Antioxidant activity of some foods containing phenolic compounds, International journal of food sciences and nutrition, 52(6), pp. 501-508.

15. Poznyakovsky V., Pomozova V., Kiseleva T., Permyakova L. (2007), Beverage Examination, Publishing House of Novosibirsk University, Novosibirsk.

16. Azlim Almey A., Ahmed Jalal Khan C., Syed Zahir I., Mustapha Suleiman K., Aisyah, M., Kamarul Rahim, K. (2010), Total phenolic content and primary antioxidant activity of methanolic and ethanolic extracts of aromatic plants leaves, International Food Research Journal, 17(4), pp. 1077-1084.

17. Padmanabhan P., Mizran A., Sullivan J. A., Paliyath G. (2016), Strawberries. Encyclopedia of Food and Health, Elsevier, pp. 193-198.

18. Irene Falcó, Patricia L. Flores-Meraz, Walter Randazzo, Gloria Sánchez, Amparo López-Rubio, María José Fabra (2019), Antiviral activity of alginate-oleic acid based coatings incorporating green tea extract on strawberries and raspberries, Food Hydrocolloids, 87, pp. 611-618.

19. Pritts M. (2017), Soft Fruits, Encyclopedia of Applied Plant Sciences (Second Edition). Volume 3, Elsevier, pp. 268-272.

20. Ángeles Trujillo-Reyes, Juan Cubero-Cardoso, Guillermo Rodríguez-Gutiérrez, Juan Francisco García-Martín, Mónica Rodríguez-Galánc, Rafael Borjab, Antonio Serrano, Fernando G. Fermoso (2019), Extraction of phenolic compounds and production of biomethane from strawberry and raspberry extrudates, Biochemical Engineering Journal, 147, pp. 11-19. 